\title{
A prospective, contralateral comparison of photorefractive keratectomy (PRK) versus thin-flap LASIK: assessment of visual function
}

This article was published in the following Dove Press journal:

Clinical Ophthalmology

19 April 20I I

Number of times this article has been viewed

Bryndon B Hatch'

Majid Moshirfarl

Andrew J Ollerton'

Shameema Sikder ${ }^{2}$

Mark D Mifflin'

'John A. Moran Eye Center, University of Utah, Salt Lake City, UT, USA;

${ }^{2}$ Wilmer Eye Institute, Johns Hopkins

University, Baltimore, MD, USA
Correspondence: Majid Moshirfar Moran Eye Center, 65 Mario Capecchi Drive, Salt Lake City, UT 84I 32, USA $\mathrm{Tel}+\mathrm{I}(80 \mathrm{I}) 58 \mathrm{I}-2352$

Fax +I (80I) 58I-3357

Email majid.moshirfar@hsc.utah.edu
Purpose: To compare differences in visual acuity, contrast sensitivity, complications, and higher-order ocular aberrations (HOAs) in eyes with stable myopia undergoing either photorefractive keratectomy (PRK) or thin-flap laser in situ keratomileusis (LASIK) (intended flap thickness of $90 \mu \mathrm{m}$ ) using the VISX Star S4 CustomVue excimer laser and the IntraLase FS60 femtosecond laser at 1, 3, and 6 months postoperatively.

Methods: In this prospective, masked, and randomized pilot study, refractive surgery was performed contralaterally on 52 eyes: 26 with PRK and 26 with thin-flap LASIK. Primary outcome measures were uncorrected distance visual acuity (UDVA), corrected distance visual acuity (CDVA), contrast sensitivity, and complications.

Results: At 6 months, mean values for UDVA (logMAR) were $-0.043 \pm 0.668$ and $-0.061 \pm 0.099$ in the PRK and thin-flap LASIK groups, respectively $(\mathrm{n}=25, P=0.466$ ). UDVA of $20 / 20$ or better was achieved in $96 \%$ of eyes undergoing PRK and $92 \%$ of eyes undergoing thin-flap LASIK, whereas $20 / 15$ vision or better was achieved in $73 \%$ of eyes undergoing PRK and $72 \%$ of eyes undergoing thin-flap LASIK $(P>0.600)$. Significant differences were not found between treatment groups in contrast sensitivity $(P \geq 0.156)$ or CDVA $(P=0.800)$ at postoperative 6 months. Types of complications differed between groups, notably $35 \%$ of eyes in the thin-flap LASIK group experiencing complications, including microstriae and 2 flap tears.

Conclusion: Under well-controlled surgical conditions, PRK and thin-flap LASIK refractive surgeries achieve similar results in visual acuity, contrast sensitivity, and induction of HOAs, with differences in experienced complications.

Keywords: photorefractive keratectomy, thin-flap LASIK, visual function

\section{Introduction}

Refractive surgery is one of the most commonly performed elective procedures and will likely maintain its popularity as ablation techniques become more refined and understanding of corneal wound healing improves. Two of the most common methods of refractive surgery are photorefractive keratectomy (PRK) and laser in situ keratomileusis (LASIK). The rapid improvement in vision and lack of postoperative pain associated with LASIK has made this the preferred option with patients compared with PRK, which has greater postoperative discomfort and prolonged recovery of visual acuity. ${ }^{1}$ Recently, there has been renewed interest in PRK because of increasing concerns of complications associated with LASIK flap creation, including dry eye, corneal ectasia, and flap tears. ${ }^{2-5}$

Thin-flap LASIK attempts to gain benefits of both techniques by creating a flap of between 80 and $90 \mu \mathrm{m} . .^{6-8}$ Use of a thinner flap results in a more biomechanically 
stable cornea and decreases incidence of ectasia given the thicker residual stroma. ${ }^{3,9}$ Cutting a thinner LASIK flap is less invasive to the nerves within the corneal stroma, decreasing the severity and duration of dry eye, possibly by preserving corneal sensation and blinking rate. ${ }^{10-14}$ Flap creation avoids corneal epithelium removal, allowing reduced healing time and less haze and scarring. ${ }^{15}$ The present contralateral study compares the outcomes of eyes that have undergone PRK or thin-flap LASIK using the VISX STAR S4 excimer laser (VISX Incorporated, Santa Clara, CA), with flaps created with intended thicknesses of $90 \mu \mathrm{m}$ using the IntraLase FS60 femtosecond laser (Abbott Medical Optics [AMO], Santa Ana, CA).

\section{Methods}

Data from myopic eyes were analyzed, with or without astigmatism, in which the dominant eye was randomized (Research Randomizer software - Urbaniak, www.randomizer.org) to PRK or thin-flap LASIK ( $90 \mu \mathrm{m}$ flap) and the nondominant eye underwent the alternative treatment. All PRK and thinflap LASIK treatments were performed using the VISX Star S4 CustomVue laser at the John A. Moran Eye Center, Salt Lake City, Utah, between February 2008 and July 2009. All surgeries were overseen by two surgeons (M.M., M.D.M.). The research protocol was approved by the University of Utah Hospital Institutional Review Board.

All patients included in this study met the US Food and Drug Administration guidelines for VISX CustomVue LASIK. Mean age of patient, 13 men and 13 women, was 30.8 years (range: $23-46$ ). Twenty-six patients (52 eyes) with stable myopia (1.5-8.5 diopters [D]) and astigmatism $(0.242-3.11 \mathrm{D})$ were enrolled in the study. Eleven patients excluded from this study had clinically significant lens opacities, previous corneal or intraocular surgery, keratoconus, unstable refraction, autoimmune disease, immunosuppressive therapy, or were pregnant or breastfeeding. Correction was made for distance and patients desiring monovision correction were excluded. Contact lenses were discontinued 2 weeks prior to screening for soft contact lens wearers and 6 weeks prior to screening for rigid gas permeable lens wearers. All patients had a preoperative examination including assessment of uncorrected distance visual acuity (UDVA), corrected distance visual acuity (CDVA), tonometry, slitlamp examination of the anterior segment, and dilated fundus examination. Manifest and cycloplegic refractions were repeated on 2 separate visits to ensure reliability and stability. Corneal topography and thickness were measured using the Orbscan II v.3.0 (Bausch and Lomb, Rochester, NY). All eyes received 5 preoperative wavefront analyses with the VISX CustomVue WaveScan aberrometer v.3.62 (Fourier) (AMO), without pharmacologic intervention, under mesopic conditions, with a minimum pupil diameter of $6.0 \mathrm{~mm}$.

The contralateral study design was made so that each eye could act as a control for the fellow eye in each patient, allowing for study groups to be well matched. There were no violations in the randomization; all patients were analyzed as originally assigned. The randomization protocol was generated before the trial and known only to the study coordinator. In all patients, the emmetropic correction target was based on manifest refraction and wavefront analysis. All flaps were created with the IntraLase FS60 femtosecond laser at $60 \mathrm{kHz}$ in a raster pattern with bed energy of $1.15 \mu \mathrm{J}$, side-cut energy of $2.00 \mu \mathrm{J}$, and pocket enabled. The flaps were created with an intended thickness of

Table I Preoperative group comparisons

\begin{tabular}{|c|c|c|c|}
\hline Parameter & $\begin{array}{l}\text { PRK } \\
(n=25)\end{array}$ & $\begin{array}{l}\text { Thin-flap LASIK } \\
(n=25)\end{array}$ & $P$ value ${ }^{a}$ \\
\hline Mean UDVA (logMAR) \pm SD & $1.286 \pm 0.312$ & $1.269 \pm 1.178$ & 0.866 \\
\hline Mean UDVA $(20 / x) \pm S D$ & $478.26 \pm 283.10$ & $480.65 \pm 301.20$ & 0.855 \\
\hline CDVA $(\log M A R) \pm S D$ & $\begin{array}{l}-0.0211 \pm 0.0564 \\
(-0.125 \text { to } 0.097)\end{array}$ & $\begin{array}{l}-0.021 I \pm 0.0564 \\
(-0.125 \text { to } 0.097)\end{array}$ & 1.00 \\
\hline $\operatorname{CDVA}(20 / x) \pm S D$ & $\begin{array}{l}19.2 \pm 2.4 \\
(15 \text { to } 25)\end{array}$ & $\begin{array}{l}19.2 \pm 2.4 \\
(15 \text { to } 25)\end{array}$ & 1.00 \\
\hline Sphere (D) \pm SD & $\begin{array}{l}-4.67 \pm 1.95 \\
(-8.50 \text { to }-1.50)\end{array}$ & $\begin{array}{l}-4.74 \pm 2.07 \\
(-7.75 \text { to }-0.60)\end{array}$ & 0.732 \\
\hline Cylinder (D) \pm SD & $\begin{array}{l}0.86 \pm 0.72 \\
(0.00 \text { to } 2.25)\end{array}$ & $\begin{array}{l}0.81 \pm 0.70 \\
(0.00 \text { to } 2.50)\end{array}$ & 0.805 \\
\hline Central corneal thickness $(\mu \mathrm{m}) \pm S D$ & $\begin{array}{l}556 \pm 29 \\
(502 \text { to } 596)\end{array}$ & $\begin{array}{l}554 \pm 27 \\
(503 \text { to } 598)\end{array}$ & 0.719 \\
\hline
\end{tabular}

Notes: Values represented as mean \pm standard deviation (range); andependent samples $t$-test.

Abbreviations: UDVA, uncorrected distance visual acuity; CDVA, corrected distance visual acuity. 
$90 \mu \mathrm{m}$, diameter of 8.4 to $9.0 \mathrm{~mm}$, superior hinge angle of $55^{\circ}$, and a side-cut angle of $70^{\circ}$. Intraoperative pachymetry or optical coherence tomography were not performed to evaluate actual flap thicknesses. If the $8.0 \mathrm{~mm}$ maximum intended ablation diameter exceeded the flap diameter, the hinge and flap were shielded during ablation.

Postoperatively, each eye undergoing thin-flap LASIK received 1 drop of gatifloxacin 0.3\% (Zymar; Allergan Inc, Irvine, CA), prednisolone acetate 1\% (Pred Forte, Allergan Inc), ketorolac tromethamine 0.4\% (Acular LS, Allergan Inc.), and a bandage soft contact lens (Softlens Plano T, Bausch and Lomb, Rochester, NY). The prednisolone acetate was continued hourly during the first preoperative day and 4 times daily for an additional 6 days. The gatifloxacin was continued 4 times daily for 1 week.

In eyes undergoing PRK all eyes had their corneas cooled with $15 \mathrm{~mL}$ of $\mathrm{BSS}\left(2.8-3.9^{\circ} \mathrm{C}\right)$ immediately following ablation. This was followed by 1 drop of a gatifloxacin $0.3 \%$ (Zymar), prednisolone acetate 1\% (Pred Forte), ketorolac tromethamine $0.4 \%$ (Acular LS) and a bandage soft contact lens (Softlens Plano T). Ketorolac tromethamine was continued 4 times a day for 3 days and then discontinued. Gatifloxacin and prednisolone acetate were continued 4 times a day for 1 week with a subsequent steroid taper over 2 to 3 months per surgeon preference. Mitomycin $\mathrm{C}$ was not administered to any patient in the study at any time. Both bandage soft contact lenses were removed simultaneously once re-epithelialization was complete, typically on postoperative days 3 to 5 .

Patients were seen 1 day, 1 week, 1 month \pm 10 days, 3 months \pm 14 days, and 6 months \pm 14 days. At all follow-up examinations, UDVA and CDVA were tested using a standard Snellen eye chart. Visual acuity was recorded in both Snellen notation and logarithm of the minimum angle of resolution ( $\log$ MAR) format. Contrast sensitivity was measured in controlled mesopic conditions at 3, 6, 12, and 18 cycles per degree (cpd) using the Vectorvision CSV$1000 \mathrm{E}$ chart (Vectorvision, Greenville, OH). Higher-order aberrations (HOAs), including coma $Z(3,1)$, trefoil $Z(3,3)$, and spherical aberration $Z(4,0)$, were measured using the CustomVue WaveScan at a mean diameter of $6 \mathrm{~mm}$. Undilated scans of both eyes were taken preoperatively and 1,3 , and 6 months postoperatively.

Primary outcome measures were UDVA, CDVA, contrast sensitivity, and complications. HOAs were measured and trended within groups as secondary measures. After the study was completed, the results were compiled and the data unmasked for statistical analysis. Refractive error, visual

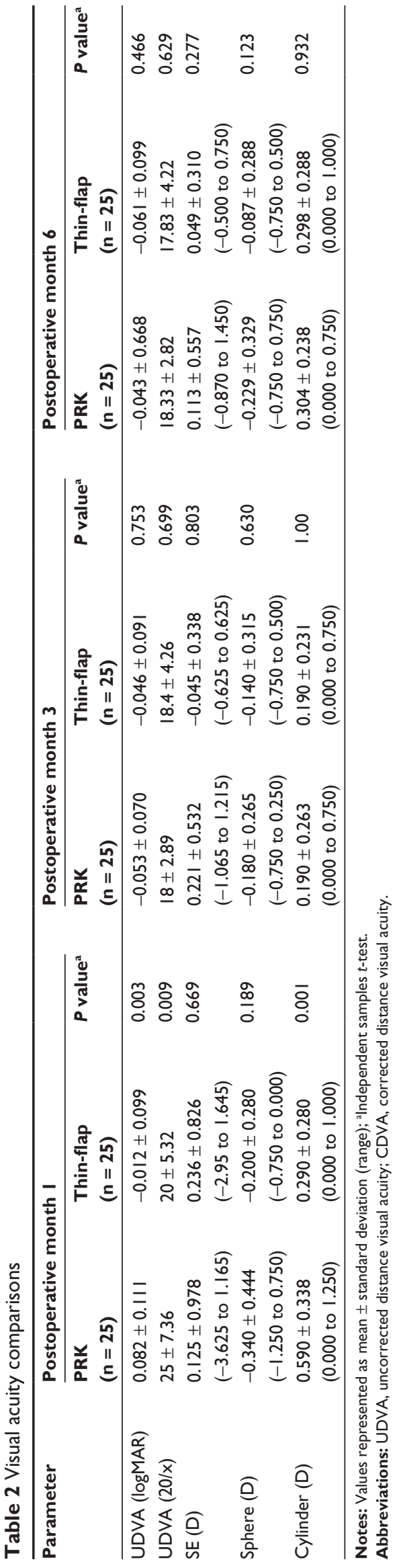


Table 3 Efficacy, predictability, and safety comparisons of PRK and thin-flap LASIK

\begin{tabular}{|c|c|c|c|c|c|c|c|c|c|}
\hline \multirow[t]{2}{*}{ Parameter } & \multicolumn{3}{|c|}{ Postoperative month I } & \multicolumn{3}{|c|}{ Postoperative month 3} & \multicolumn{3}{|c|}{ Postoperative month 6} \\
\hline & $\begin{array}{l}\text { PRK } \\
(n=25)\end{array}$ & $\begin{array}{l}\text { TF LASIK } \\
(\mathrm{n}=25)\end{array}$ & $\begin{array}{l}P \\
\text { value }^{\mathrm{a}}\end{array}$ & $\begin{array}{l}\text { PRK } \\
(n=25)\end{array}$ & $\begin{array}{l}\text { TF LASIK } \\
(\mathrm{n}=25)\end{array}$ & $\begin{array}{l}P \\
\text { value }^{a}\end{array}$ & $\begin{array}{l}\text { PRK } \\
(n=25)\end{array}$ & $\begin{array}{l}\text { TF LASIK } \\
(\mathrm{n}=25)\end{array}$ & $\begin{array}{l}P \\
\text { value }^{a}\end{array}$ \\
\hline Efficacy (UDVA) & & & 0.009 & & & 0.699 & & & 0.718 \\
\hline $20 / 15$ or better & I (4) & $7(29)$ & & II (44) & $12(48)$ & & $9(38)$ & $13(54)$ & \\
\hline $20 / 20$ or better & II (44) & $21(84)$ & & $24(96)$ & $23(92)$ & & $24(96)$ & $23(92)$ & \\
\hline $20 / 25$ or better & $19(76)$ & $24(98)$ & & $25(100)$ & $23(92)$ & & $25(100)$ & $24(96)$ & \\
\hline $20 / 30$ or better & $23(92)$ & $24(98)$ & & & $25(100)$ & & & $25(100)$ & \\
\hline $20 / 40$ or better & $24(96)$ & $25(100)$ & & & & & & & \\
\hline $20 / 50$ or better & $25(100)$ & & & & & & & & \\
\hline Predictability & & & 0.189 & & & 0.630 & & & 0.242 \\
\hline $\pm 0.50 \mathrm{D}$ of emmetropia & $19(76)$ & $23(92)$ & & $24(96)$ & $23(92)$ & & $23(92)$ & $22(88)$ & \\
\hline $\pm 1.00 \mathrm{D}$ of emmetropia & $5(20)$ & $2(8)$ & & I (4) & $2(8)$ & & $2(8)$ & $3(12)$ & \\
\hline$\pm \mathrm{I} .50 \mathrm{D}$ of emmetropia & I (4) & & & & & & & & \\
\hline Safety (CDVA) & & & 0.011 & & & 0.578 & & & 0.462 \\
\hline Loss of 2 lines & $2(8)$ & $0(0)$ & & $0(0)$ & $0(0)$ & & $0(0)$ & $0(0)$ & \\
\hline Loss of I line & $4(16)$ & $2(9)$ & & $2(8)$ & I (4) & & $0(0)$ & $0(0)$ & \\
\hline No loss of lines & $16(64)$ & $14(56)$ & & II (44) & $13(52)$ & & $9(36)$ & II (44) & \\
\hline Gain of I line & $3(12)$ & $9(39)$ & & $11(42)$ & $10(40)$ & & $15(60)$ & $13(52)$ & \\
\hline Gain of 2 lines or more & $0(0)$ & $0(0)$ & & I (4) & I (4) & & I (4) & I (4) & \\
\hline
\end{tabular}

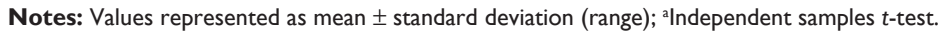

Abbreviations: UDVA, uncorrected distance visual acuity; CDVA, corrected distance visual acuity.

acuity, and HOAs were treated as continuous variables and analyzed for significance by independent $t$-tests. In all tests, $P$ values $<0.05$ were considered statistically significant. Data analysis was done using Microsoft Excel (Microsoft Corp, Redmond, WA).

\section{Results}

Mean preoperative measurements of UDVA, CDVA, sphere, and cylinder are shown in Table 1.25 of 26 patients (50 eyes) completed the study at postoperative 6 months. One eye in the thin-flap LASIK group required PRK retreatment following a flap tear and both eyes from this patient were therefore removed from analysis of visual acuity, contrast sensitivity, and HOAs as the retreatment prevented the ability to distinguish results between the 2 surgical methods. The eyes from this patient were still included in the analysis of complications.

\section{Visual acuity}

Table 2 shows visual acuity outcomes at 1, 3, and 6 months postoperatively. Statistically significant differences were found between PRK and thin-flap LASIK in UDVA at 1 month postoperatively, with thin-flap LASIK eyes showing more improvement in UDVA. Visual acuities were not statistically different between the groups at 3 or 6 months.

\section{Stability, efficacy, and predictability}

Table 3 shows stability, efficacy, and predictability outcomes postoperatively at 1,3 , and 6 months. CDVA was statistically different between groups at 1 month, with $24 \%$ of the PRK group losing a line or more from preoperative values, while $9 \%$ of eyes in the thin-flap LASIK group lost only 1 line at 1 month. No eyes in the thin-flap LASIK group lost more than 1 line. Also, 39\% of eyes in the thin-flap group gained a line by 1 month compared with only $12 \%$ of eyes in the PRK group. At 6 months $64 \%$ and $56 \%$ of eyes had gained a line or more of CDVA in the PRK and thin-flap LASIK groups, respectively $(P=0.462)$.

\section{Contrast sensitivity}

Contrast sensitivity measurements at 3, 6, 12, and 18 cycles per degree (cpd) in each group are shown in Figure 1. There were no differences between groups at any cpd at any time in the study $(P \geq 0.156)$. The thin-flap LASIK group showed no change in contrast sensitivity postoperatively $(P>0.131)$, while patients in the PRK group had a slight decrease in contrast sensitivity at 1 month seen at 3 and $12 \mathrm{cpd}(P=0.004)$ and $(P=0.025)$, respectively. At 6 months contrast sensitivity in the PRK group was still significantly decreased from baseline at $3 \mathrm{cpd}(P=0.013)$, although it did not reach a statistically significant difference at 3 months $(P=0.101)$.

\section{Complications}

Types of complications differed between the 2 groups. In the PRK group, 2 cases of epithelial defects occurred by 1 week, but had completely resolved by 6 months. Three eyes in the PRK group had mild haze appearing as early as 1 week postoperatively. 


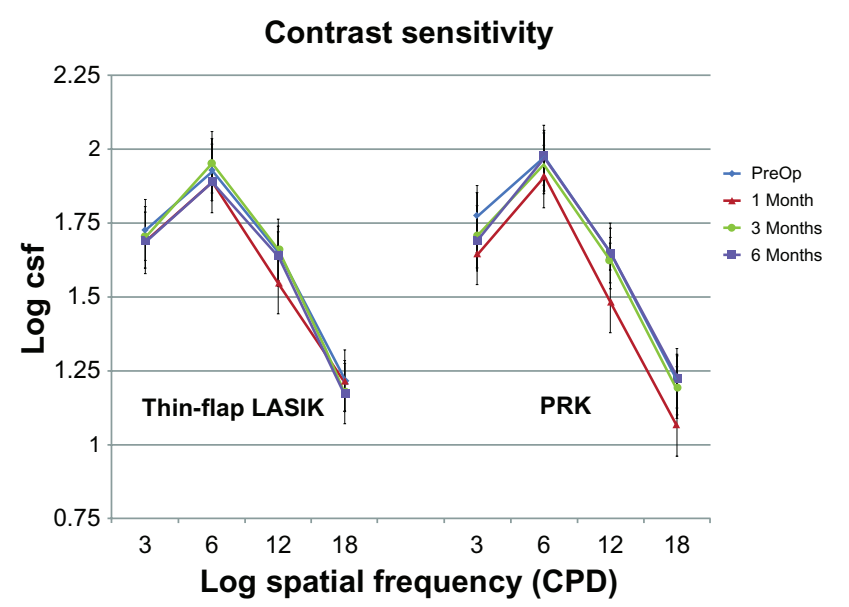

Figure I Comparison of contrast sensitivity measured at 3, 6, 12, and 18 cycles per degree (cpd) preoperatively and at postoperative I, 3, and 6 months using the Vectorvision CSV-I000E chart $(\mathrm{n}=25$ for each group, $P \geq 0.156)$.

Haze remained in only 1 eye at 6 months, but was classified as minimal and had no effect on UDVA or CDVA.

Nine eyes $(35 \%)$ in the thin-flap LASIK group experienced complications. In the thin-flap LASIK group, flap debris (1 eye), diffuse lamellar keratitis (DLK, 1 eye), and an epithelial cyst at the edge of 1 flap were observed, with no loss of UDVA or CDVA, and all resolved by 6 months. Microstriae were observed in 6 eyes, one of which was the eye described above with flap debris and the other was the eye with DLK, with no associated loss of UDVA or CDVA, with epithelial proliferation noted as filling the microstria and making them less apparent. Two eyes in the thin-flap LASIK group experienced flap tears intraoperatively - one resulting in mild flap edge scarring by 6 months that had no significant effect on visual function, and the other case affecting vision at 1 month postoperatively which was retreated with PRK at 3 months. As a result of the retreatment with the counter surgical technique, the ability to accurately compare visual acuity, contrast sensitivity, and HOAs between the 2 surgical methods was limited and both eyes from this patient were removed from analysis of these measures, but were still included in the analysis of complications.

\section{Higher-order aberrations}

At postoperative 1, 3, and 6 months, 24 (96\%), 25 (100\%), and 24 (96\%) eyes, respectively, in each group completed CustomVue WaveScan analysis. Total root-mean square (RMS) HOAs, coma, trefoil, and spherical aberrations are compared in Figure 2. There were no significant differences between groups in any HOAs throughout the study ( $P \geq 0.101)$, with all $P$ values at 6 months $\geq 0.63$. In both groups, total HOAs $(P<0.008)$, spherical $(P<0.002)$, and coma ( $P=0.008$ at 3 months; $P=0.024$ at 6 months $)$ aberrations were significantly increased compared with preoperative conditions. Trefoil showed no significant change throughout the study in either group $(P=0.298)$.

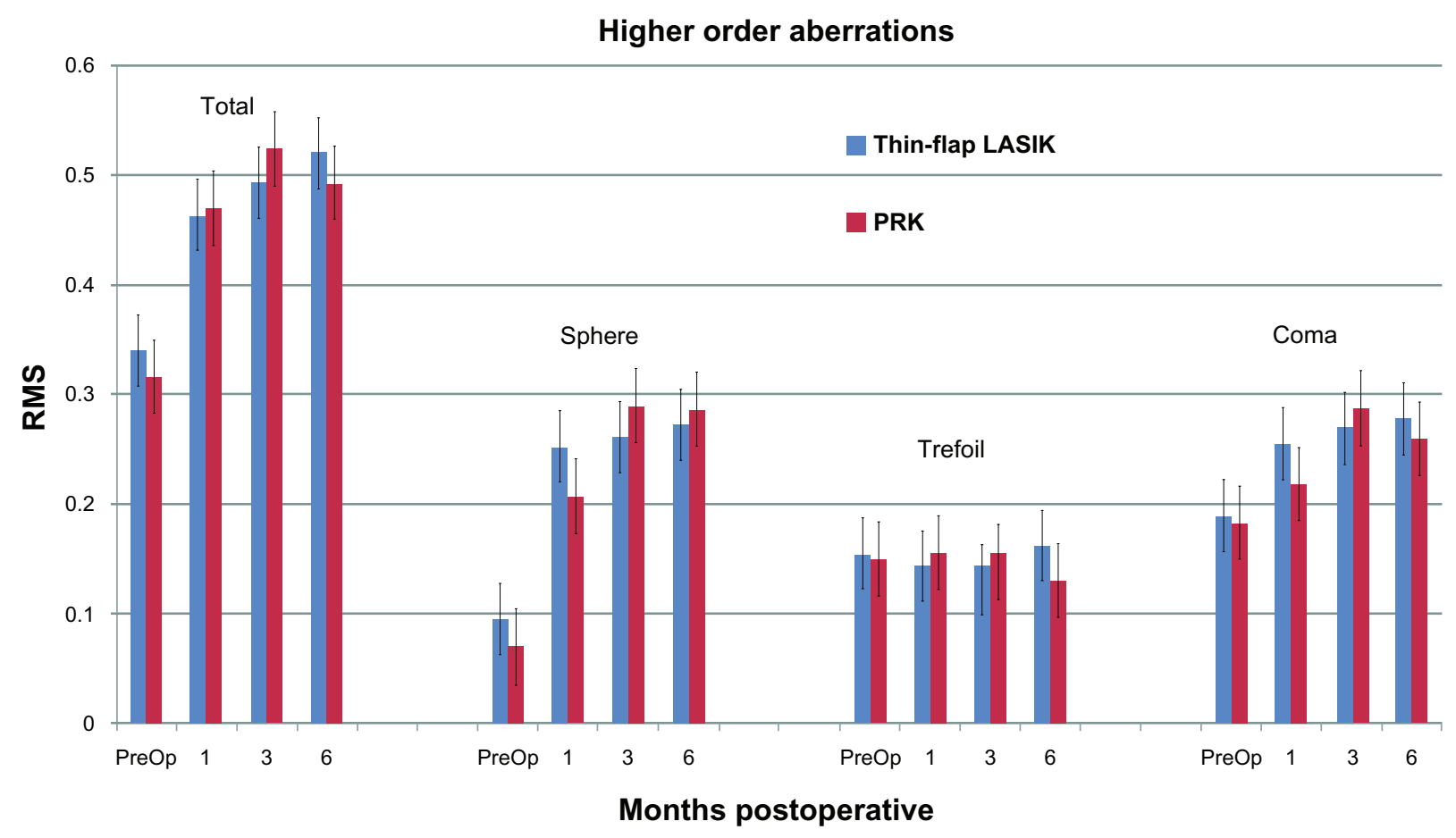

Figure 2 Comparison of ocular higher-order aberrations before surgery and at postoperative I, 3, and 6 months. Coma, Z(3,I), trefoil, Z(3,3), and spherical aberration, $Z(4,0)$, were measured using the WaveScan at a mean diameter of $6 \mathrm{~mm}(\mathrm{n}=5$ for each group, $P \geq 0.10 \mathrm{I})$. 


\section{Discussion/conclusion}

The present study confirms that PRK and thin-flap LASIK are effective surgeries for the correction of low to moderate myopia. Although thin-flap LASIK showed superior visual results in the early postoperative period there was no statistically significant difference in outcomes of UDVA, CDVA, contrast sensitivity, or total RMS HOAs between PRK and thin-flap LASIK by 6 months. In a similar study comparing PRK and thin-flap LASIK, Slade et al also found that UDVA results were better in the thin-flap group early on and equalized by 6 months. ${ }^{16}$ Our study showed a similar trend, with no significant differences in any of the primary outcomes at 6 months, and with no difference in UDVA at 3 months. Visual regression in our study was similar to outcomes in Slade's study in which $42 \%$ of the PRK group lost a line or more of CDVA and $22 \%$ of the thin-flap LASIK group lost 1 line at 1 month postoperatively.

Despite the use of custom ablation, postoperative increases in total HOAs, sphere, and coma were noted in our study, as also seen by Slade et al, although they noted that the increase in sphere and coma aberrations was significantly higher in the PRK group at 1 and 3 months postoperatively. As found in previous studies, there was no significant change found in trefoil at any time postoperatively. ${ }^{17,18}$ Our study showed no difference in induction of HOAs between groups at any time. Although increases in HOAs after refractive surgery have been correlated with decreases in contrast sensitivity in other studies, we demonstrate that increases in total RMS, sphere, and coma were seen postoperatively in both groups without a reliable decrease in contrast sensitivity. ${ }^{19,20}$ Slade's group found that contrast sensitivity was better in the thinflap group at all postoperative points in the study, which may have been related to their finding of lower induction of sphere and coma aberrations in the thin-flap group compared with the PRK group. The authors recognize that the Slade study had a larger population size ( $\mathrm{n}=50$ per group) and would have increased power to detect significant differences. Our study would have had increased power of analysis with a similar study group size, but results from analysis of HOAs would not likely change as $P$ values for all HOAs at 6 months were $\geq 0.63$. It would be difficult to make any such correlation between contrast sensitivity and HOAs from the results of this study.

A loss of CDVA has been associated with the development of corneal haze in other studies, but as mentioned above none of the patients with visual regression developed haze. ${ }^{21-23}$ Findings in other studies showing that the biomechanics of eyes that have received thin-flap LASIK treatment are indistinguishable from those of PRK have led to suggestions that thin-flap LASIK is the best approach to LASIK. ${ }^{16}$ Although the present study did not find any statistically significant differences between thin-flap LASIK and PRK in terms of visual quality at 6 months, complications dealing with flap integrity in the thin-flap LASIK group were present which are not complications found in PRK. Although PRK remains a viable option for those unable to undergo LASIK, the use of thinner flaps may eliminate some of the complications seen with traditional LASIK. Larger studies are needed to better compare the complication rates of both methods and to determine how effective thin-flap LASIK will be in achieving the benefits of PRK and LASIK while avoiding the risks associated with each method.

While thinner LASIK flaps attempt to preserve the biomechanical stability of the corneal stroma, at the same time, the flap itself becomes less stable, as was noted with the 2 flap tears and other complications occurring in the thin-flap LASIK group in this study. A study by Espandar and Meyer ${ }^{24}$ showed that most complications in flaps created by IntraLase femtosecond laser occurred at the hinge, which is where the 2 flap tears that occurred in this study. A thinner flap hinge would be biomechanically less stable and would increase the likelihood of intraoperative flap tear occurrence as well. Six of the 9 eyes with complications in the thin-flap LASIK group had microstriae, which are caused by the flattening of a weak corneal flap unable to maintain its curvature over the small area of stroma removed during ablation. The biomechanics of the flap and hinge, however, cannot be evaluated by the design of this study as analysis was done based on intended flap thickness, which has been shown to vary with the IntraLase FS60 femtosecond laser. ${ }^{25}$ The study could have been strengthened had intraoperative pachymetry or OCT been performed.

Creating a flap with increased integrity would help prevent microstriae from forming and would also provide for a stronger hinge that would be less susceptible to flap tear. Possible ways to optimize flap integrity include modification of hinge and side-cut angle creation, as well as improved planarity and microdisruption of flap edges. This will allow improved adhesion of the flap to the underlying stroma. Continued improvements in laser technology may allow for safer creation of thinner flaps, helping to provide evidence for superior outcomes in thin-flap LASIK, permitting the biomechanical stability of PRK with the visual recovery of LASIK. Custom flap formation that minimizes weak areas susceptible to tearing will be helpful in achieving this difficult balance between corneal and flap integrity. 


\section{Acknowledgment}

Supported in part by a grant to the Department of Ophthalmology at the University of Utah, Salt Lake City, from

Research to Prevent Blindness, New York, USA.

\section{Disclosure}

No author has a financial or proprietary interest in any material or method mentioned.

\section{References}

1. Shortt AJ, Bunce C, Allan BD. Evidence for superior efficacy and safety of LASIK over photorefractive keratectomy for correction of myopia. Ophthalmology. 2006;113:1897-1908.

2. Melki SA, Azar DT. LASIK complications: etiology, management, and prevention. Surv Ophthalmol. 2001;46:95-116.

3. Reynolds A, Moore JE, Naroo SA, Moore CB, Shah S. Excimer laser surface ablation - a review. Clin Experiment Ophthalmol. 2010;38: $168-182$.

4. Condon PI, O'Keefe M, Binder PS. Long-term results of laser in situ keratomileusis for high myopia: risk for ectasia. J Cataract Refract Surg. 2007;33:583-590.

5. Binder PS. Ectasia after laser in situ keratomileusis. J Cataract Refract Surg. 2003;29:2419-2429.

6. Azar DT, Ghanem RC, de la Cruz J, et al. Thin-flap (sub-Bowman keratomileusis) versus thick-flap laser in situ keratomileusis for moderate to high myopia: case control analysis. J Cataract Refract Surg. 2008;34:2073-2078

7. Slade SG. Removal of corneal tissue: why a customized sub-Bowman's flap is the best approach in LASIK. Cataract and Refractive Surgery Today. 2006;45-46.

8. Slade SG. Thin-flap laser-assisted in situ keratomileusis. Curr Opin Ophthalmol. 2008;19:325-329.

9. Randleman JB. Post-laser in-situ keratomileusis ectasia: current understanding and future directions. Curr Opin Ophthalmol. 2006;17: 406-412.

10. Beuerman RW, McCulley JP. Comparative clinical assessment of corneal sensation with a new aesthesiometer. Am J Ophthalmol. 1978;86: 812-815.

11. Beuerman RW, Schimmelpfennig B. Sensory denervation of the rabbit cornea affects epithelial properties. Exp Neuro. 1980;169:196-201.
12. Kanellopoulos AJ, Pallikaris IG, Donnenfeld ED. Comparison of corneal sensation following photorefractive keratectomy and laser in situ keratomileusis. J Cataract Refract Surg. 1997;23:34-38.

13. Xu KP, Yagi Y, Tsubota K. Decrease in corneal sensitivity and change in tear function in dry eye. Cornea. 1996;15:235-239.

14. Barequet IS, Hirsh A, Levinger S. Effect of thin femtosecond LASIK flaps on corneal sensitivity and tear function. J Refract Surg. 2008;24: 897-902.

15. Sakimoto T, Rosenblatt MI, Azar DT. Laser eye surgery for refractive errors. Lancet. 2006;367:1432-1447.

16. Slade SG, Durrie DS, Binder PS. A prospective, contralateral eye study comparing thin-flap LASIK (sub-Bowman keratomileusis) with photorefractive keratectomy. Ophthalmology. 2009;116:1075-1082.

17. Moshirfar M, Hatch BB, Chang JC, Kurz CJ, Eugarrios MF, Mifflin MD. Prospective, contralateral comparison of 120-mum and 90-mum LASIK flaps using the IntraLase FS60 femtosecond laser. J Refract Surg. 2010;13:1-9.

18. Miraftab M, Seyedian MA, Hashemi H. Wavefront-guided vs wavefront-optimized LASIK: a randomized clinical trial comparing contralateral eyes. J Refract Surg. 2010;1:1-6.

19. Yamane N, Miyata K, Samejima T, et al. Ocular higher-order aberrations and contrast sensitivity after conventional laser in situ keratomileusis. Invest Ophthalmol Vis Sci. 2004;45:3986-3990.

20. Bühren J, Martin T, Kühne A, Kohnen T. Correlation of aberrometry, contrast sensitivity, and subjective symptoms with quality of vision after LASIK. J Refract Surg. 2009;25:559-568.

21. Marshall J, Trokel SL, Rothery S. Long term healing of the central cornea after photorefractive keratectomy using an excimer laser. Ophthalmology. 1988;95:1411-1421.

22. Fagerholm P, Hamberg-Nyström H, Tengroth B. Wound healing and myopic regression following photorefractive keratectomy. Acta Ophthalmol (Copenh). 1994;72:229-234.

23. Kuo IC, Lee SM, Hwang DG. Late-onset corneal haze and myopic regression after photorefractive keratectomy (PRK). Cornea. 2004;23:350-355.

24. Espandar L, Meyer J. Intraoperative and postoperative complications of laser in situ keratolikeusis flap creation using intralase femtosecond laser and mechanical microkeratomes. Middle East Afr J Ophthalmol. 2010;17:56-59.

25. Kerizean GM, Stonecipher KG. Comparison of the Intralase femtosecond laser and mechanical keratomes for laser in situ keratomileusis J Cataract Refract Surg. 2004;30:804-811.
Clinical Ophthalmology

\section{Publish your work in this journal}

Clinical Ophthalmology is an international, peer-reviewed journal covering all subspecialties within ophthalmology. Key topics include: Optometry; Visual science; Pharmacology and drug therapy in eye diseases; Basic Sciences; Primary and Secondary eye care; Patient Safety and Quality of Care Improvements. This journal is indexed on Submit your manuscript here: http://www.dovepress.com/clinical-ophthalmology-journal

\section{Dovepress}

PubMed Central and CAS, and is the official journal of The Society of Clinical Ophthalmology (SCO). The manuscript management system is completely online and includes a very quick and fair peer-review system, which is all easy to use. Visit http://www.dovepress.com/ testimonials.php to read real quotes from published authors. 